\title{
LITERACY COMPETENCES IN CULTURAL DIVERSE CLASS- ROOMS: EXPERIENCES OF TEACHERS
}

\author{
PETER BROEDER \& MIA STOKMANS
}

Department of Culture Studies, Tilburg University, P.O. Box 90153, 5000 LE, the Netherlands

\begin{abstract}
This contribution takes a closer look at literacy competence-related problems in socially and culturally diverse classrooms. Diversity in language and reading socialization both contribute significantly to differences in literacy competences, which is something that surfaces in daily teaching practice. A survey among 169 primary and secondary school teachers in the Netherlands focused on the perspective of the teachers, since they are the ones who have to deal with the diversity in literacy. The extent of the problems the teachers indicated as being caused by their students' lack of literacy competences is considerable in all classes. During their day-to-day teaching, teachers of multicultural classes experience more problems related to literacy competences than do teachers of monocultural classes. The results indicate that it is desirable if not vital to pay attention to the acquisition of literacy competences in diverse, multicultural classrooms in teacher training and refresher courses.
\end{abstract}

Broeder, P., \& Stokmans, M. (2012). Literacy competences in cultural diverse classrooms: experiences of teachers. L1-Educational Studies in Language and Literature, 12, pp. 1-18. http://dx.doi.org/10.17239/L1ESLL-2012.04.02

Correspondence concerning this article should be addressed to Peter Broeder or Mia Stokmans, Department of Culture Studies, Tilburg University, P.O. Box 90153, 5000 LE, the Netherlands; e-mail:peter@broeder.com and m.j.w.stokmans@uvt.nl 


\section{INTRODUCTION}

Multicultural classes are a logical consequence of the dynamic unification of Europe and EC treaties relating to the free movement of persons and goods (European Parliament, 2001). As a result, differences in students' language backgrounds are quite prominent in day-to-day teaching practice. Both teachers and pupils find themselves confronted with considerable differences in students' language backgrounds and a host of problems issuing forth from this (McPake, Tinsley, Broeder, Mijares, Latomaa \& Martyniuk, 2007). Pupils not only differ in the languages they use at home; there are also vast differences between them in their proficiency in the language in which they get instruction at school. This language is often referred to simply as 'school language', but because of its high level of abstraction it is also known as 'academic language'. To do well in class, to have any hope of success in the educational system as a whole, a good command of the school language is indispensable. Most studies of the use of academic language in the classroom take a rather static perspective by analyzing linguistic and pragmatic features (Schleppegrell, 2004; Aarts, Demir \& Vallen, 2011). In this study we take a different approach. We are interested in the processes that allow pupils (according to the teachers) to construct meaning (through the academic, school language register) in different ways.

The question addressed in this study is to establish whether there are differences between the monocultural classroom and the multicultural classroom. More specifically, we seek to demonstrate that variations in literacy competences complicate the learning process for all pupils in a multicultural classroom and thus limit their chances of acquiring the desired level of proficiency. In our argumentation, we embrace a social constructivist (language) approach to education and (language) learning (Gibbons, 2002; Cobb, 2006), where the class is seen as a social system in which the learning process proceeds through interaction. In this learning process, pupils acquire literacy competences through linguistic interactions. A sufficient level of these competences is a prerequisite for the successful completion of classes in virtually any subject, and thus for school success (cf. Freeman \& Freeman, 2007).

In studies on diversity in students' literacy competences, the perspective chosen is often that of the pupil, whereby differences in literacy competences tend to be linked to socio-economic background characteristics and/or (literacy) socialization (for instance, Au, 1998; de Jong \& Leseman, 2001; Stokmans, 2007). In this study, however, we take the teacher's perspective. After all, the teacher is the person who is confronted with and recognizes diversity in literacy competences and is able to indicate what the differences are between the required competence level and the average competence level actually found in their classrooms. If these differences are large, teachers are likely to experience problems. The lesson content presented in the school language register will only partly be understood by the pu- 
pils, and as a result their chances of success may be greatly reduced. By making an inventory of the problems experienced and the success rate as assessed by the teachers, it can be made plain how urgent the problems in this area really are. Through a survey the experiences and opinions of Dutch teachers in the Netherlands who teach in monocultural or multicultural classrooms are established. This might bring to surface hidden problems and tensions in an educational system (such as in the Netherlands) in which L2-classes (Dutch as a second language) and mother tongue classes (in migrant and minority languages) have become an exception (McPake et al., 2007).

\subsection{Linguistic interaction in a teaching context}

To ensure a broad perspective on the issue, the framework we present (see Figure 1 ) is based on two very different paradigms. The first starts from a socialconstructivist perspective (Vygotsky, 1987; Wilkinson \& Silliman, 2000; Painter, 2001), with the following premises:

1) Learning is seen as a social activity. Interpersonal behaviour is the basis for new conceptual understanding.

2) Learning is integrated. There is a strong relation between oral and written language.

3) A prerequisite for learning is interaction and participation in classroom activities. Engaged pupils are more motivated and have the best chance of being successful at school.

The second perspective is that of a communication model (Fill, 2011, p. 33) which focuses on diversity in cultural background and indicates how diverse social systems (identified as areas of experience) affect linguistic interactions (content of the lesson and interaction in the classroom).

In the framework presented, as summarized in Figure 1, learning is the result of interaction (visualized as circles) between two persons of different cultural backgrounds. In this case, in Figure 1, these are a teacher and a pupil, but it could also be between pupils. According to social-constructivism, all experiences (in all social domains; in lessons, at school in general, in society as a whole) add to the competences, skills and knowledge a person brings to the social context and shape the linguistic interaction. In Figure 1, the experiences are visualized in three triangles. 
Figure 1: A model of linguistic interaction in a socially diverse learning and teaching context.

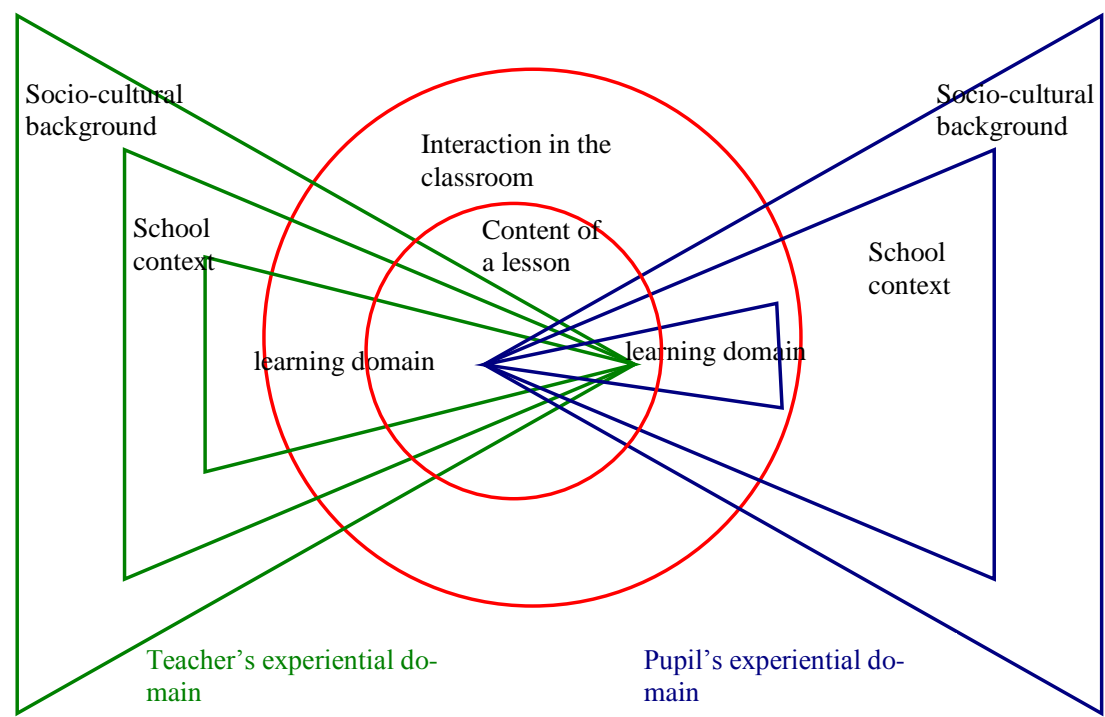

\subsection{The learning domain.}

In the first (smallest) triangle we find the experiences in the learning domain, consisting of subject-specific proficiency, competences, and personal experiences with the subject taught. The linguistic interaction taking place in this domain revolves around knowledge specific of the 'school subject' taught and the competences related to it (Gibbons, 2002).

\subsection{The school context}

The second, somewhat larger triangle comprise the broader social context of the school, where we find experiences, ways of doing things, and language use that extend beyond the subject classes but that are still school-specific. The linguistic variety in which pupils are taught is part of this broader social context, and is known as the school language register or as "academic language" (Schleppegrell, 2004; Aarts, Demir \& Vallen, 2011).

\subsection{The socio-cultural background.}

The third and largest triangle stands for the broader socio-cultural background, which includes the experiences (including customs and values) and language use 
(including street slang) typical of this broader social context (home, the neighbourhood).

Figure 1 shows a situation in which there is a considerable difference between the pupil's linguistic, social and cultural background (on the right) and that of the teacher (on the left). There is little overlap between the domains that indicate the register, the school context and the socio-cultural context. In a situation like this, the interaction between the pupil and the teacher is bound to be problematic because there is little overlap between their subject proficiencies, their literacy competences, and their experiences.

The experiential domain of the teacher will be reflected in the language register they tend to use in teaching their subject, as well as in the examples they will choose to illustrate the lesson content and in their elaboration on these examples.

\subsection{Content of a lesson.}

In presenting the content of their lessons teachers will draw on their own experiential domain and try to take into account the average knowledge, competences, and experiences of the pupils in their classrooms. This is illustrated in Figure 1: the centre of the circle indicating the lesson content is located slightly more towards the teacher. If the triangles of the experiential domains have little in common, teachers will have to adjust their lessons accordingly. This becomes problematic if the pupils in the classroom differ markedly in their cultural backgrounds, school careers, familiarity with the subject domain, and literacy competences. However, as Figure 1 also shows, the interaction in the classroom is more a matter of the individual pupils, which is why the centre of this circle is located slightly to the right of that of the smaller circle of the lesson content. Pupils will interpret the content of a lesson from their own experiential domain. Teachers can give additional feedback if it turns out that a pupil did not get the content right. If pupils have little experience with the subject the classes are about, they will not be able to make use of the relevant register for that subject. They will most likely make use of the register of a related area of expertise, of the more general school register or of the register that is based on their own experiential domain (home, the street).

\subsection{Interaction in the classroom.}

What teachers in an educational setting want to achieve, and what Figure 1 is meant to illustrate, is to get across to their pupils a certain part of the proficiencies and competencies specific to a particular learning domain. In this process, the linguistic interaction is bound to be determined or at least influenced by the experience domains of the teacher, which the pupils for the most part do not share. In this linguistic interaction, literacy competences other than those specific to the learning domain will also play a role, competences that originate from the broader educational context or that are embedded in a particular socio-cultural back- 
ground. Naturally, if pupils' literacy competences lag behind the competences expected by the teachers, these teachers will experience problems explaining and illustrating the content of their lessons and the pupils will experience problems interpreting the lesson content, resulting in a situation in which the learning process is seriously impaired. Based on this theoretical elaboration, we formulate four hypotheses:

Hypothesis 1: Teachers of multicultural classes experience more problems resulting from diversity in literacy competences in communicating the content of their lessons than do teachers of monocultural classes.

Hypothesis 2: Teachers experience more problems for language classes than for other subjects (social sciences, natural sciences, mathematics, and technical classes).

Hypothesis 3: Teachers of multicultural classes expect lower levels of literacy competences in their pupils, than do teachers of monocultural classes.

Hypothesis 4: Compared to teachers of monocultural classes, teachers of multicultural classes expect fewer pupils to reach the level of literacy competences necessary for successfully attaining the level required in the learning domain.

Before we investigate these hypotheses, we will first carefully explore the notion of 'literacy competences'. In this study, we restrict ourselves to receptive literacy competences. We will illustrate that these competences determine the pupils' interpretation and thus also their comprehension of the lesson content.

\subsection{Literacy competences in a school context}

Every discipline taught at school uses abstract concepts and specialist terms to describe specific phenomena without referring to specific situations or cases. Besides this, these descriptions will generally be quite precise, and should be understood and interpreted as such by the pupils in the classroom. To be able to do so, pupils will have to possess the necessary cognitive skills (literacy competences) that are typical of linguistic interactions in an educational context. To get an idea of the kind of competences we are talking about, we take recourse to the cognitive skills to be involved in understanding written texts, that is, processes and strategies of reading. The PIRLS study (Progress in Reading Literacy Study) focuses on the achievement and reading experiences of children in 42 countries in 2006, and in 52 countries in 2011. In the PIRLS assessment for the domain of reading to acquire and use information, four types of comprehension processes are conceptualized (Mullis, Martin, Kennedy, Trong \& Sainsbury, 2009): 
1) Focus on and retrieve explicitly stated information;

2) Make straightforward inferences;

3) Interpret and integrate ideas and information;

4) Examine and evaluate content, language and textual elements.

In constructing meaning the reader focuses on specific ideas, makes inferences, interprets and integrates information and ideas, and examines and evaluates text features (Mullis et al., 2009). We will go into these four types of comprehension processes one by one and explain them by literacy competences of the pupil.

Competence 1: Focus on and retrieve explicitly stated information. The first type of competence focuses on the information contained in the content of the lesson. What is the lesson about, and what is being said about it? Pupils should be able to recognize the intended information in the text or in what is being communicated. Questions that can be answered at this level of comprehension are: who does what, where and when? This level of competence is to do with vocabulary and meaning analysis at the sentence level.

Competence 2: Make straightforward inferences. In the second type of competence, pupils not only make use of essential information in a particular part of a text, they can also combine information that is given at difference places in a text in order to establish the chronological sequence of events, simple causal relationship between events, or a line of argumentation. In addition, pupils can draw straightforward inferences that allow them to fill in gaps in the line of reasoning. These competences are essential, since they cover all kinds of meaning that are not expressed directly or explicitly in communication.

Competence 3: Interpret and integrate ideas and information. In the third type of competence, the interpretation process is supplemented with 'extra-textual' information. Pupils interpret the information gathered from a text and integrate it with their own ideas, knowledge and experiences. The resulting interpretation is idiosyncratic since all pupils take part in the communication process starting from their own domain of experiences (social and cultural background). Important inferences that are made here include the implications of the information for the pupil or the extent to which ideas expressed in the text are consistent with ideas in other texts. Pupils reflect on what is communicated in the light of their own experiential domain (experiences, knowledge, norms and values).

Competence 4: Examine and evaluate content, language and textual elements. In the last type of cognitive competence, pupils are able to take a bird's eye view of what is presented to them. The interpretation of the text is evaluated in the light of the type of text. In doing so, pupils use their knowledge of linguistic conventions, genres, textual structure, and familiarity with the author's point of view (the 
source) to arrive at a critical appraisal of the text. On the bases of this kind of competence, pupils can adjust the meaning of the text, or look at it from another perspective.

The above-mentioned types of cognitive competences allow us to describe literacy competences more precisely. We are dealing with procedural knowledge (processes and strategies), and thus with necessarily vague boundaries. The order in which these competences are applied may be context-specific (e.g., educational context, persuasive context) or depend on the purpose of the interpretation (e.g., learning for an exam). Thus, if a pupil wants to trace specific information in a text fast, for instance, being familiar with the genre of the text and the specific structure that is characteristic of that genre can be a great help.

\section{RESEARCH METHOD}

This study was conducted in the Netherlands (summer 2009 - summer 2010). It can be characterized as a two-sided descriptive investigation. On the one side we make an inventory of the extent to which teachers experience problems related to diversity in literacy competences in their day-to-day teaching practice. On the other side we look at pupils' achievements on literacy competence. As was said before, we look at these topics from the perspective of the teacher.

\subsection{Respondents}

The online questionnaire on the opinions and perceptions of teachers was completed by 169 teachers active in Dutch primary and secondary education. Table 1 summarizes important characteristics of the sample. Most teachers in the sample have been teaching for many years, but they are not very familiar with teaching multicultural classes. Moreover, in their original training and in any later refresher courses, hardly any attention at all was paid to 'teaching in a multilingual (multicultural) classroom'. This is all the more striking because as little as $19 \%$ of the teachers are teaching classes with L1-Dutch pupils only; $29 \%$ are teaching classes in which the majority (75\%) of the class are L1-Dutch pupils; $24 \%$ are teaching classes where about half the class are L1-Dutch pupils; $16 \%$ are teaching classes where as little as $25 \%$ of the pupils have Dutch as $\mathrm{L} 1$; and $12 \%$ are teaching classes with hardly any (less than 10\%) L1-Dutch pupils.

Also differences in educational level of the pupils were taken into account. As the description of the sample shows (Table 1), approximately $38 \%$ of the respondents were teachers at primary schools, $49 \%$ teachers taught at junior high schools or vocational training schools and $11 \%$ teachers taught at senior high school level. 
Table 1: Characteristics of the teachers in the sample

\begin{tabular}{|c|c|c|}
\hline Characteristic & Count & \\
\hline Age & 160 & 42.5 years old $(s d=12.55)$ \\
\hline Gender & 163 & $67 \%$ women \\
\hline Nr of yrs. active in education & 159 & $16.2(\mathrm{sd}=12.05)$ \\
\hline Nr of yrs. teaching a multilingual class & 156 & $8.09(\mathrm{sd}=9.76)$ \\
\hline Educational level & 140 & $\begin{array}{l}39 \% \text { primary teaching training; } \\
36 \% \text { secondary teaching training } \\
25 \% \text { master's degree or equivalent }\end{array}$ \\
\hline $\begin{array}{l}\text { Attention paid to teaching multilingual } \\
\text { classes in original education }\end{array}$ & 164 & $1.2(s d=1.07)$ (none:1; 5-points) \\
\hline $\begin{array}{l}\text { Attention paid to teaching multilingual } \\
\text { classes in refresher courses }\end{array}$ & 163 & $1.59(\mathrm{sd}=1.10)$ (none:1; 5-points) \\
\hline Teaching practice & 135 & $\begin{array}{l}38 \% \text { primary school } \\
49 \% \text { vocational training / junior } \\
\text { (first three years) high school } \\
13 \% \text { senior (fourth year and up) high } \\
\text { school }\end{array}$ \\
\hline
\end{tabular}

\subsection{The questionnaires}

We investigated teachers' opinions and perceptions using an online questionnaire that was part of the Eucim-project (Broeder \& Stokmans, 2009; Roth, Duarte, Broeder \& Stokmans, 2010). The following elements in the questionnaire are relevant here:

- the teachers' background characteristics (as reported in Table 1);

- the problems with diversity in literacy competences encountered by the teacher in day-to-day teaching practice;

- the extent to which the encountered problems occur in all classes taught (both language classes and other subject classes);

- $\quad$ the pupils' level of literacy competences as judged by the teacher;

- the level of literacy competences necessary to complete the classes successfully according to the teacher. 


\subsection{Literacy competences}

In order to make an inventory of the problems as they are perceived by the teachers, we distinguish three receptive literacy competences:

- Vocabulary: understanding of words;

- Meaning analysis: understanding of intra-textual information at the sentence level and at the paragraph level;

- Comprehension: understanding of intra- and extra-textual information.

These three literacy competences are derived from the cognitive comprehension processes described in the introduction (as in the PIRLS-assessment) and made more manageable for the teachers' judgments (i.e., word-sentence-paragraphtext). Table 2 presents an overview of the specific indicators of the literacy competences distinguished. For each competence, as summarized on the left side of Table 2 , the teachers were asked to indicate the extent to which problems were perceived ("to what extent does diversity on this literacy competence complicate teaching in your situation?" 5-point scale, "Not at all = 1", "very much = 5"). Next, they were asked to indicate the extent to which these literacy problems (in general) occurred in classes on particular subjects, the subjects investigated being Dutch language, modern languages, social sciences, natural sciences, mathematics or arithmetic, ICT, and technical skills classes.

Table 2: Receptive literacy competences and indicators

\begin{tabular}{|c|c|c|}
\hline Literacy competence & & Indicator \\
\hline $\begin{array}{l}\text { Understanding of } \\
\text { words? } \\
\text { (vocabulary) }\end{array}$ & $\checkmark$ & $\begin{array}{l}\text { Frequently occurring words in the subject domain (taking into } \\
\text { account the school year). } \\
\text { Infrequently used words in the subject domain (taking into } \\
\text { account the school year). }\end{array}$ \\
\hline $\begin{array}{l}\text { What does the text liter } \\
\text { ly say? } \\
\text { (meaning analysis) }\end{array}$ & $\begin{array}{l}\checkmark \\
\checkmark\end{array}$ & $\begin{array}{l}\text { Meaning at the sentence level: Who, what, when. } \\
\text { Meaning at the paragraph level: Who does what, why, to } \\
\text { what purpose in a particular context? }\end{array}$ \\
\hline $\begin{array}{l}\text { What is the intention } \\
\text { of the text? } \\
\text { (comprehension) }\end{array}$ & $\begin{array}{l}\checkmark \\
\checkmark \\
\checkmark\end{array}$ & $\begin{array}{l}\text { Inferences: Empathy with persons in the story and usefulness } \\
\text { of the information for the pupil. } \\
\text { Line of argument: recognize implicit and explicit arguments } \\
\text { and ideas; completeness of argumentation; Correspondence } \\
\text { with ideas of the reader. } \\
\text { Understanding of global text features (type of text, } \\
\text { communicative purpose, global content and tone of voice of } \\
\text { the text) and adjusting the interpretation accordingly. }\end{array}$ \\
\hline
\end{tabular}


The impact of literacy competences on finishing the classes successfully was established in two ways. Firstly, for each of the seven indicators of literacy competences, as summarized on the right side of Table 2, teachers were asked to indicate the achievement level of their pupils ("What is the achievement level of the pupils on each of the competences in your class, taking into account the level that might be expected for the particular school year, i.e., at this stage of their education?" 5 point scale, "worse than expected" = 1, "roughly as expected" = 3, "much better than expected" = 5). Secondly, teachers could indicate, for each literacy competence, the percentage of pupils that reach the necessary level to complete their classes successfully ("What percentage of your pupils reaches the level in these competences necessary to be able to finish your classes successfully?" 5-point scale, "almost nobody = 1", "about 50\% = 3", "almost everyone = 5").

\section{RESULTS}

The perceptions and opinions of teachers of multicultural classrooms were contrasted with those of teachers of monocultural classrooms. To this effect, the sample was divided into two groups: $48 \%$ of the teachers taught in monolingual classrooms (predominantly L1-Dutch pupils) while $52 \%$ taught in a multilingual classroom ( $50 \%$ or more of the pupils in the classroom do not have Dutch as L1).

\subsection{Problems with diversity on literacy competences}

The central questions with regard to problems related to diversity in literary competences in this section are: 'To what extent are they perceived?' (Hypothesis 1), and 'Are they universal for classes in all subjects?' (Hypothesis 2).

Table 3 gives an overview of the results with respect to the first hypothesis. An analysis of variance (ANOVA) with the factors Dutch as L1 (more versus less than $50 \%$ L1-Dutch) and educational level (primary school, junior, and senior high school levels) indicated that there are significant differences between classes for all global literacy competences as judged by the teacher (Vocabulary: $F(1,120)=5,48$; $p<$ 0,$05 ; \eta 2=0,04$. Meaning analysis: $F(1,119)=5,44 ; p<0,05 ; \eta^{2}=0,04$. Comprehension: $F(1,121)=8,91 ; p<0,05 ; \eta 2=0,07)$. In classrooms with less than $50 \%$ L1Dutch pupils, teachers experience significantly more problems with respect to all literacy competences. Furthermore, teachers at primary schools and at the junior high school level experience problems to the same extent, but both experience significantly more problems than do teachers at the senior high school level (Vocabulary: $F(2,120)=4,92 ; \mathrm{p}<0,05 ; \eta 2=0,08$. Meaning analysis: $F(2,119)=6,23 ; \mathrm{p}<$ $0,05 ; \eta 2=0,09$. Comprehension: $F(2,121)=4,66 ; p<0,05 ; \eta 2=0,07)$. In addition, Table 3 suggests that teachers experience more problems as the literacy competences get more cognitively complex. The more information (in the text or extratextual) students need to integrate, the more problems are experienced. This is in 
line with what could be expected on the basis of the theoretical model as summarized in Figure 1.

Table 3: Average literacy problems with diversity in literacy competences (5-point scale; 1=none at all, 5=very much; standard deviations in parentheses)

\begin{tabular}{|c|c|c|c|c|}
\hline Literacy competence & $\begin{array}{l}\text { Classroom } \\
\text { diversity* }\end{array}$ & Primary school & $\begin{array}{l}\text { Junior } \\
\text { high school }\end{array}$ & $\begin{array}{l}\text { Senior } \\
\text { high school }\end{array}$ \\
\hline \multirow[t]{2}{*}{ Vocabulary } & Mono & $3.42(1.31)$ & 3.43 (1.07) & $2.73(0.79)$ \\
\hline & Multi & $4.15(0.95)$ & 3.76 (1.07) & $2.80(0.84)$ \\
\hline \multirow[t]{2}{*}{ Meaning analysis } & Mono & $3.56(1.20)$ & 3.54 (1.08) & $2.82(0.87)$ \\
\hline & Multi & $4.04(0.85)$ & 4.09 (1.03) & $2.60(1.14)$ \\
\hline \multirow[t]{2}{*}{ Comprehension } & Mono & $3.72(1.41)$ & 3.57 (1.03) & $2.91(0.83)$ \\
\hline & Multi & $4.23(0.82)$ & $4.21(0.93)$ & $3.20(0.84)$ \\
\hline
\end{tabular}

The next question concerned the extent to which the problems encountered as a result of diversity in literacy competences were subject-specific. The results are presented in Table 4, which specifies the differences between monocultural (more than $50 \%$ Dutch as L1) and multicultural (50\% or less Dutch as L1) classrooms and between educational levels. Analyses of variance (ANOVA) yielded unexpected similarities and differences.

For language classes, the problems are serious (on average 4.00 for Dutch and 3.5 for modern languages on a 5-point scale) and do not differ significantly between mono- and multicultural classrooms (Dutch: $F(1,118)=0,18 ; p>0,05$. Modern languages: $F(1,103)=0,05 ; p>0,05)$. However, significant differences emerged between educational levels (Dutch: $F(2,118)=3,94 ; \mathrm{p}<0,05$. Modern languages: $F$ $(2,103)=6,21 ; p<0,05)$. For Dutch language classes, the extent of the problems perceived at primary schools and at the junior high school level was similar; fewer problems were encountered at the senior high school level. For modern languages, teachers reported a similar amount of problems at the junior and senior high school level; fewer problems were encountered at primary schools.

For the social and natural sciences, the problems were also serious (overall 3.8 for the social sciences and 3.5 for the natural sciences on a 5-point scale). For these subjects no differences can be noted between mono- and multicultural classrooms (Social sciences: $F(1,102)=0,53 ; p>0,05$. Natural sciences: $F(1,95)=2,38 ; p>$ 
$0,05)$. There were also no differences between the educational levels (Social sciences: $F(2,102)=2,35 ; p>0,05$. Natural sciences: $F(2,95)=1,89 ; p>0,05)$.

Table 4: Average literacy problems for specific classes (5-point scale; 1=none at all, 5=very much; standard deviations in parentheses)

\begin{tabular}{|c|c|c|c|c|}
\hline Subject & $\begin{array}{l}\text { Classroom } \\
\text { diversity* }\end{array}$ & Primary school & $\begin{array}{l}\text { Junior } \\
\text { high school }\end{array}$ & $\begin{array}{l}\text { Senior } \\
\text { high school }\end{array}$ \\
\hline \multirow[t]{2}{*}{ Dutch language } & Mono & $3.74(1.20)$ & $4.30(0.95)$ & $3.27(1.42)$ \\
\hline & Multi & $4,26(0.81)$ & $4.06(0.99)$ & $3.40(1.14)$ \\
\hline \multirow[t]{2}{*}{ Modern languages } & Mono & $2.71(0.85)$ & $4.15(0.91)$ & $3.27(1.01)$ \\
\hline & Multi & $3.44(1.09)$ & $3.61(1.17)$ & $3.40(1.52)$ \\
\hline \multirow[t]{2}{*}{ Social sciences } & Mono & $3.88(1.09)$ & $3.81(0.96)$ & $3.27(0.91)$ \\
\hline & Multi & $4.31(0.87)$ & $3.65(0.95)$ & $4.00(0.71)$ \\
\hline \multirow[t]{2}{*}{ Natural sciences } & Mono & $3.67(1.29)$ & $3.32(1.07)$ & $3.36(0.92)$ \\
\hline & Multi & $4.07(0.99)$ & $3.48(1.01)$ & $4.20(0.84)$ \\
\hline \multirow[t]{2}{*}{ Mathematics, arithmetic } & Mono & $3.00(1.28)$ & $2.92(1.12)$ & $2.82(1.40)$ \\
\hline & Multi & $3.44(0.73)$ & $3.30(0.95)$ & $3.80(1.09)$ \\
\hline \multirow[t]{2}{*}{ ICT } & Mono & $2.60(1.12)$ & $2.48(0.96)$ & $2.73(0.91)$ \\
\hline & Multi & $2.93(0.79)$ & $3.04(1.06)$ & $2.80(1.30)$ \\
\hline \multirow[t]{2}{*}{ Practical courses } & Mono & $2.86(1.10)$ & $2.64(1.07)$ & $2.91(1.14)$ \\
\hline & Multi & $2.77(1.09)$ & $2.75(0.94)$ & $3.00(1.41)$ \\
\hline
\end{tabular}

\footnotetext{
* monocultural classroom $=$ more than $50 \%$ L1-Dutch pupils;

multicultural classroom $=$ less than $50 \%$ L1-Dutch pupils
}

For mathematics (arithmetic), the problems reported were moderate (overall 3.15 on a 5-point scale). The analysis of variance for these subjects indicated a significant difference in the problems reported between mono- and multicultural classrooms, that is more problems being reported in multicultural classrooms $(F(1,97)=$ $4,91 ; p<0,05)$. For these subjects there were no differences between the educational levels distinguished $(F(2,97)=0,14 ; p>0,05)$.

For practical skills and ICT classes, the problems reported were less serious (overall 2.77). The practical skills courses show no differences between the monoand multicultural classrooms $(F(1,92)=0,05 ; p>0,05)$ and educational sector $(F$ $(2,92)=0,36 ; p>0,05)$. In contrast, for the ICT classes differences are reported: less 
problems being reported in the monocultural classroom $(F(1,98)=4,19 ; p<0,05)$, for all educational sectors $(F(2,94)=0,03 ; p>0,05)$.

\subsection{The level of literacy competences and success rates}

This section deals with the third and fourth hypotheses. We first examine students' achievement level on each of the literacy competences as judged by the teacher, and we subsequently go into the level necessary to complete classes successfully according to the teacher. The results for hypothesis 3 , the achievement levels on literacy competences as judged by the teacher, are reported in Table 5.

Table 5: Achievement levels on literacy competences as judged by the teacher (5-point scale; 1 = worse than expected, 3 = roughly as (to be) expected, 5 = much better than expected; standard deviations in parentheses)

\begin{tabular}{|c|c|c|c|c|}
\hline $\begin{array}{l}\text { Indicators } \\
\text { of literacy }\end{array}$ & $\begin{array}{l}\text { Classroom } \\
\text { diversity* }\end{array}$ & Primary school & $\begin{array}{l}\text { Junior } \\
\text { high school }\end{array}$ & $\begin{array}{l}\text { Senior } \\
\text { high school }\end{array}$ \\
\hline \multirow[t]{2}{*}{ Vocabulary: frequent words } & Mono & $3.27(0.79)$ & $2.96(1.09)$ & $3.33(0.71)$ \\
\hline & Multi & $2.87(1.23)$ & $2.68(1.06)$ & $3.00(1.41)$ \\
\hline \multirow[t]{2}{*}{ Vocabulary: infrequent words } & Mono & $2.73(1.10)$ & $2.33(0.87)$ & $3.00(0.93)$ \\
\hline & Multi & $2.36(0.90)$ & $2.30(0.72)$ & $2.50(0.58)$ \\
\hline \multirow[t]{2}{*}{ Meaning: sentence level } & Mono & $3.14(0.86)$ & $2.92(1.02)$ & $3.22(0.67)$ \\
\hline & Multi & $2.64(0.95)$ & $2.54(0.96)$ & $2.50(1.00)$ \\
\hline \multirow[t]{2}{*}{ Meaning: paragraph level } & Mono & $3.00(0.88)$ & $2.87(0.95)$ & $3.11(0.78)$ \\
\hline & Multi & $2.47(0.70)$ & $2.54(0.88)$ & $2.75(0.96)$ \\
\hline \multirow[t]{2}{*}{ Inferences } & Mono & $3.15(0.69)$ & $2.75(0.94)$ & $3.25(0.71)$ \\
\hline & Multi & $2.50(0.98)$ & $2.56(0.89)$ & $2.75(0.50)$ \\
\hline \multirow[t]{2}{*}{ Line of argument } & Mono & $3.00(0.91)$ & $2.76(0.97)$ & $3.33(1.00)$ \\
\hline & Multi & $2.53(0.52)$ & $2.46(0.86)$ & $2.50(0.58)$ \\
\hline \multirow[t]{2}{*}{ Global meaning text } & Mono & $3.27(0.70)$ & $2.84(0.89)$ & $3.33(1.00)$ \\
\hline & Multi & $2.75(1.07)$ & $2.25(0.84)$ & $3.00(0.96)$ \\
\hline
\end{tabular}

Firstly, teachers of classrooms with less than 50\% L1-Dutch pupils reported low levels of achievement on all literacy competences; all averages were lower than 3, 
which means that these classrooms score lower than teachers would expect given the school year.

Secondly, the differences between the mono- and multicultural classrooms are significant except for vocabulary (Frequent words: $F(1,101)=2,42 ; p>0,05$. Infrequent words: $F(1,96)=1,41 ; p>0,05$. Meaning at sentence level: $F(1,97)=6,00 ; p<$ 0,$05 ; \eta 2=0,06$. Meaning at section level: $F(1,94)=5,38 ; p<0,05 ; \eta 2=0,05$. Inferences: $F(1,90)=4,37 ; p<0,05 ; \eta 2=0,05$. Line of argument: $F(1,88)=5,33 ; p<0,05$; $\eta 2=0,06$. Global meaning of the text: $F(1,97)=8.82 ; p<0,05 ; \eta 2=0,08)$.

What is remarkable is that no differences were found between the educational levels, except for the scores on the global meaning of texts (Frequent words: $F$ $(2,101)=0,89 ; p>0,05$. Infrequent words: $F(2,96)=1,68 ; p>0,05$. Meaning at sentence level: $F(2,97)=0,38 ; p>0,05$. Meaning at section level: $F(2,94)=0,33 ; p>$ 0,05 . Inferences: $F(2,90)=0,91 ; p>0,05$. Line of argument: $F(2,88)=1,11 p<0,10$. Global meaning of the text: $F(2,97)=3,99 ; p<0,05 ; \eta 2=0,08)$. On global meaning of the text, pupils at primary schools and at the junior high school level show a similar achievement level, but the level is lower than that of pupils at the senior high school level.

In the last analysis, reported in Table 6, we go into the proportion of pupils that achieve the necessary level on a literacy competence to finish the classes successfully.

Firstly, Table 6 shows that teachers of monocultural classrooms expect more pupils to attain the level of literacy competences necessary to finish the classes successfully than is the case with teachers of multicultural classrooms. For all literacy competences distinguished this difference is significant. (Frequent words: $F$ $(1,89)=9,13 ; p<0,05 ; \eta 2=0,09$. Infrequent words: $F(1,85)=12,10 ; p<0,05 ; \eta 2=$ 0,13 . Meaning at sentence level: $F(1,84)=17,52 ; p<0,05 ; \eta 2=0,17$. Meaning at section level: $F(1,82)=13,94 ; p<0,05 ; \eta 2=0,15$. Inferences: $F(1,79)=14,40 ; p<$ 0,$05 ; \eta 2=0,15$. Line of argument: $F(1,80)=22,07 ; p<0,05 ; \eta 2=0,22$. Global meaning of the text: $F(1,83)=13,91 ; p<0,05 ; \eta 2=0,14)$.

In addition, the table shows that the percentage of pupils (in both types of classrooms) that attain the necessary level decreases as the literacy competence gets more complex. In the case of classrooms with more than 50\% L1-Dutch pupils, this proportion is still approximately $60 \%$. However, in the case of classrooms with fewer than 50\% L1-Dutch pupils, the percentage drops below 50\% (corresponding to 3 on the 5-point scale). Again, there are no differences between educational levels (Frequent words: $F(1,89)=0,83 ; p>0,05$. Infrequent words: $F(1,85)=0,92$; $p>0,05$. Meaning at sentence level: $F(1,84)=0,96 ; p>0,05$. Meaning at section level: $F(1,82)=2,19 ; p>0,05$. Inferences: $F(1,79)=0,68 ; p>0,05$. Line of argument: $F(1,80)=1,29 ; p>0,05$. Global meaning of the text: $F(1,83)=0,52 ; p>0,05)$. 
Table 6: Average proportion of pupils that attain the level necessary to finish the classes successfully as judged by the teacher (5-point scale; $1=$ less than 10\%, $3=50 \% ; 5=$ almost $100 \%$; standard deviations in parentheses)

\begin{tabular}{|c|c|c|c|c|}
\hline $\begin{array}{l}\text { Indicators } \\
\text { of literacy }\end{array}$ & $\begin{array}{l}\text { Classroom } \\
\text { diversity* }\end{array}$ & Primary school & $\begin{array}{l}\text { nior } \\
\text { gh school }\end{array}$ & $\begin{array}{l}\text { Senior } \\
\text { high school }\end{array}$ \\
\hline \multirow{2}{*}{$\begin{array}{l}\text { Vocabulary } \\
\text { frequent words }\end{array}$} & Mono & \multirow{2}{*}{$\begin{array}{l}4.38(0.65) \\
3.10(1.41)\end{array}$} & $4.14(0.94)$ & $4.13(0.84)$ \\
\hline & Multi & & $3.80(1.04)$ & $3.75(0.96)$ \\
\hline \multirow{2}{*}{$\begin{array}{l}\text { Vocabulary } \\
\text { infrequent words }\end{array}$} & Mono & 3.85 (0.99) & 3.59 (1.14) & $3.57(0.79)$ \\
\hline & Multi & $2.58(1.07)$ & $3.25(0.89)$ & $2.50(0.58)$ \\
\hline \multirow{2}{*}{$\begin{array}{l}\text { Meaning at } \\
\text { sentence level }\end{array}$} & Mono & $4.23(0.44)$ & $4.00(0.86)$ & $3.88(0.84)$ \\
\hline & Multi & $2.74(1.15)$ & $3.42(1.02)$ & $3.75(0.50)$ \\
\hline \multirow{2}{*}{$\begin{array}{l}\text { Meaning at } \\
\text { paragraph level }\end{array}$} & Mono & $3.92(0.76)$ & $3.85(0.99)$ & $3.75(0.89)$ \\
\hline & Multi & 2.47 (1.01) & $3.38(1.01)$ & $3.50(0.58)$ \\
\hline \multirow[t]{2}{*}{ Inferences } & Mono & $3.64(0.92)$ & $3.57(1.12)$ & $3.86(0.90)$ \\
\hline & Multi & $2.50(0.89)$ & $3.00(0.98)$ & $2.75(0.50)$ \\
\hline \multirow[t]{2}{*}{ Line of argument } & Mono & $3.83(0.84)$ & $3.59(1.01)$ & $3.62(1.06)$ \\
\hline & Multi & $2.14(0.66)$ & $3.04(0.99)$ & $2.50(0.58)$ \\
\hline \multirow[t]{2}{*}{ Global meaning text } & Mono & $4.23(0.60)$ & $3.86(0.91)$ & $3.75(0.89)$ \\
\hline & Multi & $2.71(1.21)$ & $3.42(1.05)$ & $3.25(0.50)$ \\
\hline
\end{tabular}

\section{CONCLUSION AND DISCUSSION}

The overall conclusion must be that the problems encountered by teachers in the area of literacy competences are considerable, both in classrooms with predominantly L1-Dutch pupils and in those with mainly L2-Dutch pupils. They are, however, decidedly more serious in the latter group. At primary schools and at the junior high school level, the competences of word knowledge (vocabulary) and of meaning analysis in particular are experienced as being most problematic, as is illustrated by a score of about 3.5 on a five-point scale for monolingual classes, and a score of 4 or more for classes with predominantly L2-Dutch pupils. That teachers of multicultural classrooms should be confronted with problems related to pupils' literacy competences is a natural outcome and therefore predictable, but what was far less 
obvious from the outset was the extent of the problems experienced, which can only be qualified as serious ( 4 on a 5 -point scale).

The problems experienced at the senior high school level are considerably less serious, and the difference between mono-and multicultural classes is also far less pronounced there. There are a number of factors that might account for this decrease in literacy problems experienced. The length of the pupils' school careers might play a role here (more experience in the school context), as well as the pupils' socio-economic background (larger probability of the parents having a high social status, which affects literacy competences acquired in primary socialization), and last but not least their intelligence. In further research, more attention will have to be paid to those factors that are closely related to the development of literacy competences.

The problems related to literacy competences are not limited to language classes, but extend also to classes in the social sciences and the natural sciences. This is true for mono- as well as multicultural classrooms. The problems are less severe in mathematics and ICT classes, even though here too multicultural classrooms are experienced as being more problematic than monolingual ones.

On the basis of the theoretical framework, we expected that literacy competences would affect the probability of pupils finishing classes successfully. We first examined the achievement level required on each of the literacy competences distinguished. At primary schools and the senior high school level, teachers of multicultural classrooms reported that on average their pupils scored below the level that could be expected given the school year, while teachers of monocultural classrooms reported that on average their pupils scored more or less as could be expected. A striking result was that teachers at the junior high school level reported that their pupils almost across the board (mono- was well as multicultural classes) scored below the level that could be expected, but with multicultural classes still scoring markedly lower than monocultural classes.

This pattern of differences between mono- and multicultural classrooms is mirrored in the proportion of pupils that reach the necessary level to complete the classes successfully. Classrooms with predominantly L2-Dutch pupils showed a smaller percentage attaining the necessary level on each of the literacy competences to finish the classes successfully.

The differences between mono- and multicultural classrooms turn out to be structural and considerable. In primary schools, the differences often amount to more than $20 \%$ (one full point on a 5 -point scale), and about $10 \%$ ( 0.5 point on a 5 point scale) at the junior high school level. At the senior high school level, monocultural classes still have a higher expected success rate, but the differences are quite small where simple literacy competences are concerned (vocabulary) and increase when literacy competences get more complex (a difference of almost $20 \%$ by inference).

These results indicate that it may be a good idea to start paying serious attention to the acquisition of literacy competences in diverse, multicultural classrooms 
in teacher training and refresher courses. If we take a look at the number of teachers that reported having taken a course on teaching multicultural classrooms in their original teacher training and in refresher courses, we can only conclude that most teachers have not had any or hardly any training at all in this area. The urgency of the problem is underscored by the fact that the problems encountered are particularly serious in primary schools, where the foundation is laid for the pupils' future school careers.

\section{ACKNOWLEDGMENTS}

We would like to thank Hans Verhulst, members of the EUCIM-TE group, and two anonymous reviewers for valuable discussions and comments.

\section{REFERENCES}

Aarts, R., Demir, S., \& Vallen, T. (2011). Characteristics of language register occurring in caretaker-child interaction: development and validation of a coding scheme. Language Learning, 64, 1173-1221. http://dx.doi.org/10.1111/j.1467-9922.2011.00664.x

$\mathrm{Au}, \mathrm{K}$. (1998). Social constructivism and the school literacy learning of students of diverse backgrounds. Journal of Literacy Research, 30, 297-329. http://dx.doi.org/10.1080/10862969809548000

Broeder, P., \& Stokmans, M. (2009). Teacher education needs analysis: the Netherlands. EUCIM-TE project (www.eucim-te.eu).

Cobb, T. (2006). Constructivism, applied linguistics, and language education. In K. Brown (Ed.), Encyclopedia of language and linguistics (pp. 85-88). Oxford: Elsevier. http://dx.doi.org/10.1016/B0-08044854-2/01593-5

Europees Parlement (2001). Feiten over de Europese Unie. [Facts about the European Union.] (http://www.europarl.europa.eu/factsheets/2 $30 \mathrm{nl} . \mathrm{htm}$ )

Fill, C. (2011). Essentials of marketing communication. New Jersey: Prentice Hall.

Freeman, Y., \& Freeman, D. (2007). Four keys for school success for elementary English learners. In J. Cummins \& C. Davison (Eds.), International handbook of English language teaching (pp 349-364). New York: Springer. http://dx.doi.org/10.1007/978-0-387-46301-8_25

Gibbons, P. (2002). Scaffolding language, scaffolding learning. Teaching second language learners in the mainstream classroom. Portsmouth, NJ: Heinemann.

De Jong, O., \&, Leseman, P. (2001). Lasting effects of home literacy on reading achievement in school. Journal of School Psychology, 39, 389-414. http://dx.doi.org/10.1016/S0022-4405(01)00080-2

McPake, J., Tinsley, T., Broeder, P., Mijares, L., Latomaa, P. \& Martyniuk, W. (2007). Valuing All Languages in Europe. Graz: ECML.

Mullis, I., Martin, M., Kennedy, A., Trong, K. \& Sainsbury, M. (2009). PIRLS 2011 Assessment framework. Boston: TIMSS \& PIRLS International Study Center Lynch School of Education, Boston College.

Painter, C. (2001). Learning through language in early childhood. London: Classell Academic.

Roth, H-J., Duarte, J., Broeder, P., \& Stokmans, M.J.W, et al.. (2010). European core curriculum for inclusive academic language teaching (IALT): an instrument for training pre-and in-service teachers and educators). EUCIM-TE project (www.eucim-te.eu).

Schleppegrell, M. (2004). The language of schooling: a functional linguistic perspective. London: Lawrence Erlbaum Associates.

Stokmans, M. (2007). De casus Bazar: Effectmeting van een leesbevorderingsproject. [The case Bazar: Effects of a reading promotion project.] Delft: Eburon. (Stichting Lezen, 8).

Vygotsky, L.S. (1987). Collected works, Volume 1. New York: Plenum. 
Wilkinson, L., \& Silliman, E. (2000). Classroom language and literacy leaning. In Kamil, M., Mosenthal, P., Pearson, P. \& Barr, R. (Eds.), Handbook of reading research, Volume III (pp. 339-360). London: Lawrence Erlbaum Associates. 